\title{
Literature in digital environments: changes and emerging trends in Australian school libraries
}

\author{
Judy O'Connell \\ Courses Director, School of Information Studies, Faculty of Education, Charles Sturt \\ University, Australia. \\ juoconnell@csu.edu.au \\ Dr Jenni Bales \\ Adjunct Lecturer, School of Information Studies, Faculty of Education, Charles Sturt \\ University, Australia \\ jbales@csu.edu.au \\ Pru Mitchell \\ Manager, Information Services, Australian Council for Educational Research; Adjunct \\ Lecturer, School of Information Studies, Faculty of Education, Charles Sturt University, \\ Australia \\ pmitchell@csu.edu.au
}

\begin{abstract}
Igniting a passion for reading and research is core business for school libraries, inevitably placing the library at the center of the $21^{\text {st }}$ century reading and learning experience. It is in this context that digital literature creates some challenging questions for teachers and librarians in schools, while the emergence of digital technology and/or device options also offers a great many opportunities. Collection development in school libraries encompasses an understanding of the need to contextualize these e-literature needs within the learning and teaching experiences in the school. The Australian Library and Information Association's 2013 statement Future of collections 50:50 predicted that library print and ebook collections in libraries would establish a 50:50 equilibrium by 2020 and that this balance would be maintained for the foreseeable future. This statement from the Australian professional body raised the need to know more about e-collections in school libraries. For teacher librarians in Australian schools, the nature of online collections, and the integration of ebooks into the evolving reading culture is influenced by the range and diversity of texts, interfaces, devices, and experiences available to complement existing print and media collections or services. Management and budget constraints also influence e-collections. By undertaking a review of the literature, a discussion of the education context, and a critical analysis of the trends evidenced by national survey data, this paper presents an overview of the changes and emerging trends in digital literature and ebook collections in school library services in Australia today.
\end{abstract}


Keywords: eBooks, eReading, School libraries, Collection development, Learning ecology

Like the history of libraries around the world, school libraries also have a long history reaching back to medieval times. While the physical expression of the idea of a school library has undergone great change, the idea itself is not new. The library has been seen as the 'pivot' or 'center' of the school for several hundred years, over time increasing in size and sophistication of organization and administration (Clyde 1981).

A major shift in the fabric of possibilities for school libraries in Australia took place in the latter part of the 20th century, commencing in 1968 for secondary schools, and 1973 for primary schools. Through to the mid-1980s school libraries were provided for by the Commonwealth Government, with funding for the necessary buildings, equipment, trained teacher-librarians, centralized services, books and other resources (Reynolds \& Carroll 2012). In another wave of funding, the Australian Government's Building Education Revolution stimulus funding resulted in as many as 3017 library projects by 2010 , of which 2,650 were new library facilities (DEEWR 2011).

Learning takes place across the life spaces of home, school and community and includes physical and virtual spaces transformed through technology. This results in a learning ecology in each school that is an expression of a set of contexts comprised of a unique configuration of activities, material resources, technology fluencies, and the interactions that emerge from them (Barron, 2006). The goal of any school library, big or small, regional or city, is to respond to these needs and provide the school with a collection that meets the leisure, learning and teaching requirements of its community, within the limits of fiscal and organizational constraints.

The role of the teacher librarian is to promote books, reading and research in old and new ways (Gordon, 2010); to nurture a learning ecology that supports all literacies relevant to reading, writing, interaction and culture both past and present (Gogan \& Marcus, 2013); and, in so doing respond to an information renaissance that is rewiring tacit and explicit knowledge and embedding a new culture of learning (Thomas \& Brown, 2011). School libraries that adapt to the digital needs of their community not only continue to build a reading culture in the school, but facilitate divergence and convergence in media. This supports the motivation, differentiation, variation in platforms, collaboration and connections necessary for the new learning ecology (Lamb \& Johnson, 2010; Hay \& Foley, 2009; Gogan \& Marcus, 2013; Marcoux \& Loertscher, 2009).The fundamental process of learning at the heart of our school libraries is as complex and changeable as the spaces, formats and pedagogies that are the essence of education today.

The Centre for International Scholarship in School Libraries <http://cissl.rutgers.edu/> provides a summary of the extensive body of international research which substantiates that school libraries and teacher librarians help young people learn, and also notes the considerable body of research that has explored how dimensions of reading are enhanced when school librarians provide access to reading materials, promote reading, and integrate literacy with instruction (Todd and Gordon 2010). School libraries are therefore important in 
helping to deliver quality education in Australia by igniting the passion for reading and research.

\section{School Library Collections}

Collections have to remain responsive to the learning and teaching needs within the school. Educationally contextualized social and learning needs help to shape decisions in response to cultural diversity, including age, gender, disability, family context, sexual preference, and socio-economic status, in a genuine and non-tokenistic way (Strick, 2013). In keeping with collection development principles as outlined by Johnson (2014, p. 3), school library staff take responsibility for selecting materials in all formats for acquisition and access, reviewing devices, and negotiating contracts to acquire or access eresources. However, the changing impact and formational influence of technology, online media, formats and media devices is part of the story of change. Now school libraries can embrace a range of 'eproducts' in the quest to provide a timely means to guide research, curriculum needs, reading and literacy experiences in schools.

\section{Reading in digital environments}

A fundamental requirement of learning is to be able to read. But what does 'read' mean in a 21st century paradigm? Lamb (2011) argues that reading goes beyond interpreting text to also include graphics, sound, motion, and other kinds of symbols in addition to or instead of text. This interpretation is supported by the Australian Curriculum: English which states that students 'listen to, read, view, speak, write, create and reflect on increasingly complex and sophisticated spoken, written and multimodal texts across a growing range of contexts with accuracy, fluency and purpose' (ACARA, 2014, par. 1). If Australian schools are to address this national directive then it is imperative that ebooks are incorporated into the reading and literature programs of schools as well as being available for students' personal reading choices. How well school libraries are addressing this challenge is influenced by a number of factors.

After years of conjecture and a variety of failed products, Amazon's Kindle introduced in 2007 was the first popular dedicated ebook reader. Now a reader can buy and download a book from their internet-enabled device with just a few clicks, and be reading immediately. Ebooks are on dedicated devices, smartphones, laptops, and it is possible to immediately share our opinions with social networks such as Goodreads. With Amazon reporting ebook sales outstripping print for the first time in 2011 (Rapaport, 2011), authors and publishers are seeking to move beyond the traditional print-style format of books and are experimenting with new forms of digital literature, with varying degrees of success.

With all these changes teacher librarians and library staff have begun to question and experiment with making ebooks and ebook readers available to the school community.

"How teacher librarians select, promote, maintain, and evaluate e-book collections, especially in the face of a constantly changing market, waxing and waning publisher restrictions on e-publication use, a staggering number of e-book file formats, and an evolving e-reader market, remains a huge challenge. But most of us see that the future of the book is digital, and we need to figure this out or get left behind (Johnson, 2013, p. 31)". 
Texts have moved from the single form of print to multiforms of text.

"Electronic texts have the potential to reduce educational expenses because they can be produced and stored at less cost than print texts. Additionally, portable, accessible libraries provide students with opportunities to read and to study in diverse locations at any time. Electronic texts can be found in increasing numbers of school libraries and classrooms where they are not only enhancing teaching and learning; they are also profoundly changing the signature pedagogy of reading literacy instruction (Felvegi \& Matthew, 2012, p. 40)".

In responding to pedagogical goals, teachers need to clearly identify what the digital experience can offer that print does not. Research on successful reading practice conducted prior to digitization remains relevant when the focus is on engagement with texts.

Rosenblatt's (1995) research into reader-response theory, first published in the 1930s, continues to underpin current literacy teaching. Rosenblatt differentiates between efferent reading (for literal and factual meaning) and aesthetic reading, where the reader's attention turns inwards to focus on literary enjoyment, engagement and involvement with the text. Enhanced ebooks are ideally suited to aesthetic reading as they encourage multiple perspectives, interpretations and levels of engagement to more fully immerse the reader. Ebooks can encourage deep reader response for both individual reading and classroom teaching. Vandergrift (1996) argues for the power of a community of readers to develop into an interpretive community. These principles continue to be relevant and enhanced by the fusion of technology - interactive whiteboards and electronic multimodal texts - in the classroom to support teaching strategies such as interactive read-alouds

\section{What is an ebook?}

Lamb (2011) and Larson (2009) have examined the multiple forms in which ebooks can be accessed and the following definitions have been informed by their work. These differences in multimodal texts each contribute in unique ways to the digital reading environment. The term 'ebook' has layers of meaning beyond the more traditional construct of an ebook as an electronic version of a print book with a linear structure that can be read or listened to on an ereader, tablet or on a computer, and may require software to make it accessible. Other forms of ebooks include:

- etextbooks as electronic versions of print textbooks. It may include images, maps and exercises with added tools for bookmarking and note-taking. Etextbooks may be available in an online format with embedded multimedia elements, links to related internet sites, quizzes and tests.

- enhanced ebooks, including

- interactive storybooks that maintain a linear story structure with the addition of interactive features such as audio, video and glossary functionality. Related activities and games may be included.

- hypertexts and interactive ebooks in nonfiction and fiction genres that o may include images, maps, audio, and video elements and links to related websites and games to extend the reading experience.

- transmedia ebooks are multimodal, multimedia, non-linear stories that encourage active participation through a range of connected resources (e.g playing cards, websites, maps or online clues). (O'Connell, Bales \& Mitchell, in press) 
Each of these ebook formats has relevance for students as the progress along the learning continuum from when they start school through to completion of their secondary education.

\section{National survey on ebooks in Australian schools}

In 2014, members of the Australian education community contributed to a survey on ebooks, titled 50:50 by 2020 Ebook Trends in Australian Schools, to collect data about current use of digital book content in schools. The survey sought schools' opinions on trends for the next 5 years, in order to gain a school library perspective on the Australian Library and Information Association's (2013) statement that library and print ebook collections would establish a 50:50 equilibrium by 20:20. To facilitate the collection of useful comparative data, the survey was framed to incorporate questions that aligned with, and expanded upon, the 2013 Survey of Ebook Usage in U.S. School (K-12) Libraries (School Library Journal, 2014) and the Australian School Library Survey (Softlink, 2014a). The survey was made available online, and was open to all Australian schools from all states and territories, across government, Catholic and independent sectors. The survey ran for three weeks commencing mid October 2014, providing a total of 450 responses.

\section{School library e-futures}

Public media have reported instances around the world where a school library space has been closed in a policy of 'gone digital'. Media hype does not include any research or positive evidence that this move has merit - perhaps the opposite. Rather, research has shown that online access and the internet has a crucial role to play in education, and that the role of the school library becomes more important. A well-resourced library becomes a 'hub for learning' and integral to the school. A telling example was reported from New Zealand:

"In 2003, Cambridge High School dismantled its library in favor of a $\$ 1.5 \mathrm{~m}$ cyber cafe. The move was short-lived. The cafe never opened and two years later, under a new principal, the library was restored. e-books and the internet complement rather than replace printed books and present no more of a challenge than audio books, video and the internet have - other than the cost". (Neale, 2011)

The Softlink (2014b) Australian School Library Survey (which received 1380 responses) provided a useful snapshot of ebook trends. Key findings showed that

- $49 \%$ of schools with eBooks started their collection in the last year

- In $201315 \%$ of school library collections indicated that eBooks accounted for more than $5 \%$ of their collection. In 2014 , this number has risen to $20 \%$

- $53 \%$ of respondents said that it is 'Very Important' or 'Important' for them to implement an eBook strategy for their library in 2015

- $54 \%$ of school libraries are planning on buying eBooks in 2015

Responses from the 50:50 in 20:20 survey showed a similar trend, with $18.6 \%$ respondents in 2014 with a collection consisting of ebooks (of any kind). Of these $93.75 \%$ were fiction resources, $76.79 \%$ were non-fiction resources, $42.86 \%$ were reference resources and 47.32 were teacher resources. This growth trend is reflected by increased percentage allocation to 
ebooks in the school library resource purchasing budget, with $2.6 \%$ allocating more than a quarter of the budget in 2013, 5.9\% in 2014 and $11.79 \%$ in 2015.

In other words, ebook resourcing demonstrates an important emerging trend, particularly in relation to collection size. Australian school library collections reported in the $50: 50$ by 2020 survey showed only $34 \%$ school libraries to have collections of $10,000-14,999$ total resources, and $66 \%$ with $15,000-30,000$ total resources in the library collection.

However, it is important to note that the number, and even proportion of ebooks available in a school, is sometimes hidden by the fact that access is not limited to individual 'borrowers', and is not a one-to-one association. Whole classes can engage with the same ebook in the classroom as a part of their language and learning area curriculum, or small sections of a digital text may be incorporated into a lesson. From a school's perspective, the priority for an ebook collection is the quality of the collection and its alignment with teaching methodology, rather than on how many ebooks are available in a collection.

Some school libraries have preferred to invest in audio versions of texts which offer an additional multimedia format. Cahill and Richey (2014) report that while there is limited research into the value of audiobooks to literacy development and content knowledge of listeners, there is evidence from publishers that audiobooks are popular in the 18-24 year old market. The $50: 50$ by 2020 Survey showed that only $20 \%$ of schools with ebooks included audiobooks in their collection, and for only $3 \%$ of these did the audiobook component make up more than $10 \%$ of their digital collection. Most of these schools with audiobooks had enrolments of 750-999 students.

Another aspect of school library ebook collections is highlighted by the $16 \%$ of respondents who indicated that student or staff-created ebooks were a feature of their collection. Reid (2013) explores the educational values of student-created ebooks in the primary school and McAllan (2013) outlines how secondary students create nonfiction ebooks to demonstrate their learning on a topic. However, the potential to create targeted, customized resources internally that support student and teacher self-publishing brings additional responsibilities for management of access and authority control within the library catalogue or digital delivery systems

Textbooks associated with traditional teaching styles require many students to have simultaneous, long-term access to the same content. The trend found in Australian schools was for students to access etextbooks online or through an app provided by the publisher or textbook aggregator service, usually on an annual subscription basis. Digital textbooks were in use in $60 \%$ of surveyed secondary schools and $67 \%$ of combined primary/secondary schools, with $2 \%$ of these being totally digital in terms of textbooks. See Figure 1. 


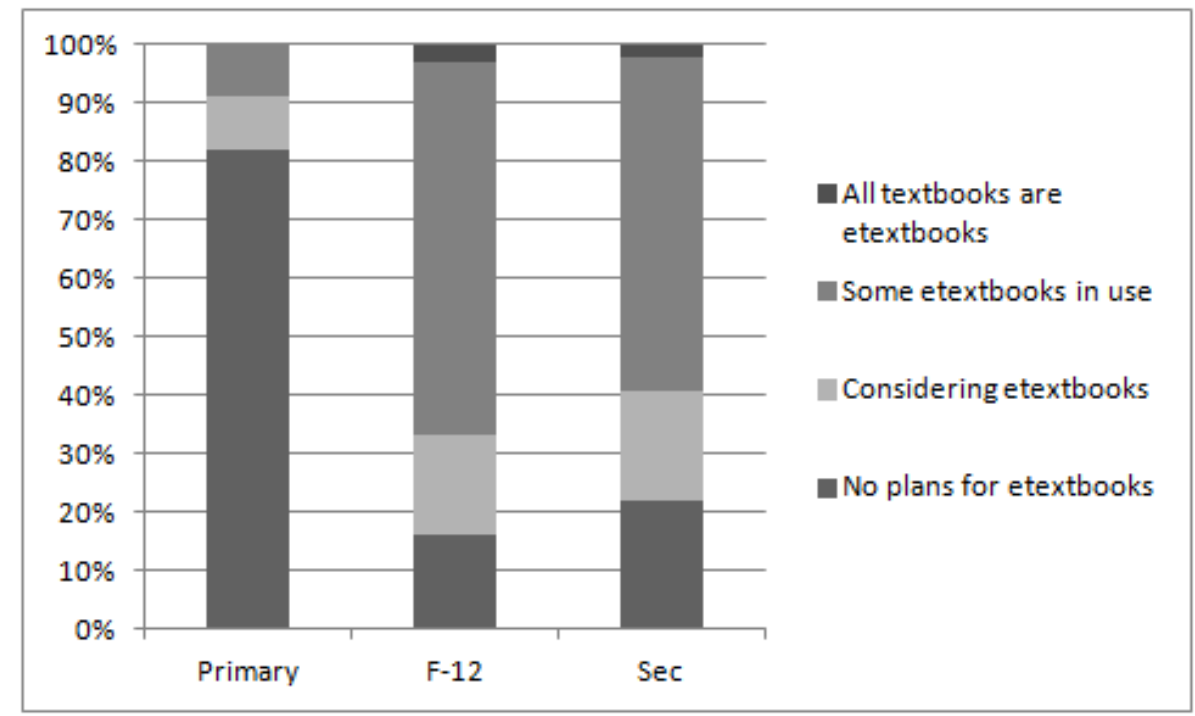

Figure 1. Implementation of etextbooks in Australian schools by level of schooling

In a quarter of secondary and combined primary/secondary schools, parents were responsible for purchasing etextbooks. In the remainder, either the school library or subject departments took responsibility for acquiring and managing school-owned etextbooks. This was a marked point of difference with primary schools, where less than $10 \%$ of schools were using etextbooks, and where parents paid for the content in only $6 \%$ of cases.

While the transition to etextbooks challenged existing models of acquisition and management for schools, there was less educational change involved for teachers in the textbook model of one book to one student. Some students reported a preference for access to both physical and digital formats of their textbooks, recognizing benefits specific to each format. Enhanced ebooks, on the other hand, with their media-rich interactivity, support both a 'one book to many students' model of teaching, or a model where one student device contains many ebooks or apps.

Figure 2 reveals there was limited evidence of teachers harnessing this form of enhanced ebook content in teaching, with only $21 \%$ of this sample accessing book apps or online literature collections despite the fact that many of these are free. The availability of online literature subscription services provides teachers with an opportunity to use traditional printbased literacy practices with a whole class (one to many) as a scaffold for a later introduction to digital reading experiences for independent readers. 


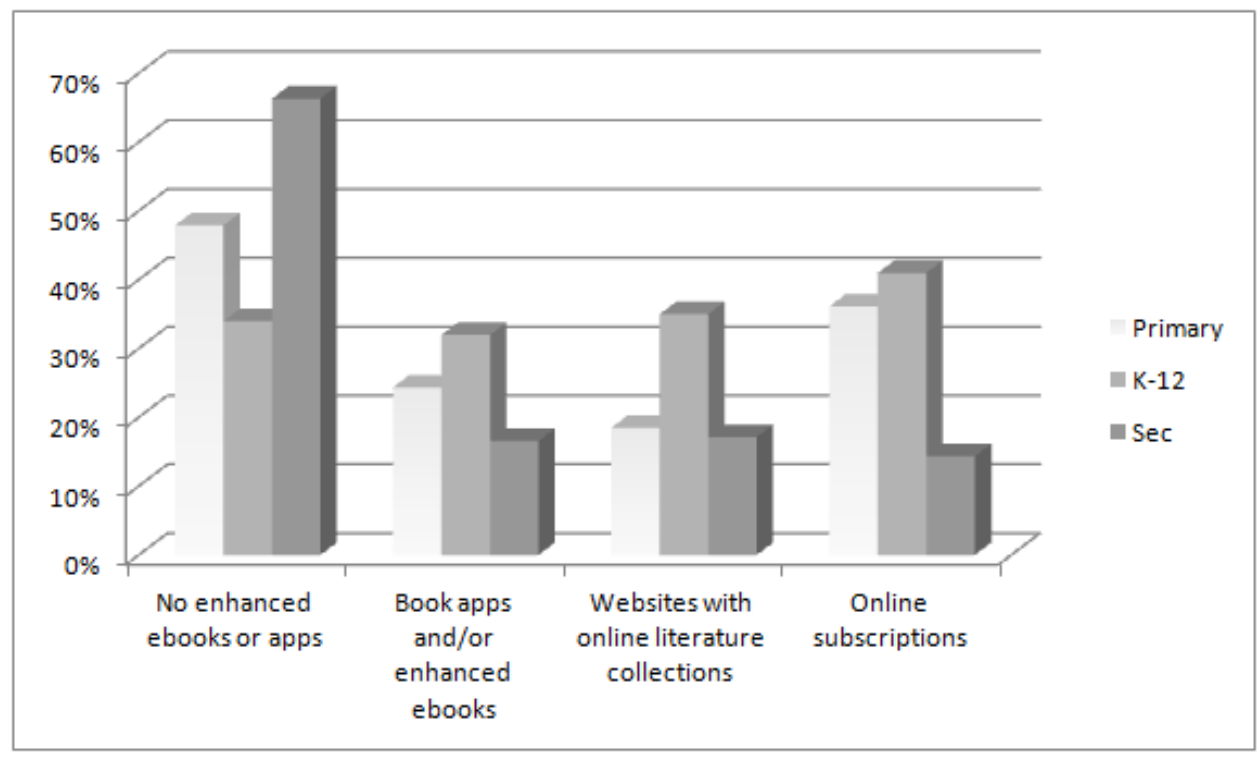

Figure 2. Use of enhanced ebooks or apps according to level of school

\section{Impact of technology}

Many students come to school with a wealth of experience in the use of a range of digital technologies for personal entertainment, learning and social interaction (Bain and Weston, 2012, p. 3). Students from Kindergarten through to Year 12 have grown up with technology and see it a standard aspect of life. Yet, on entering the school gates, these devices may be banned, have limited access or be non-existent. In this scenario, 'today's education system faces irrelevance unless we bridge the gap between how students live and how they learn' (Partnership for 21 Century Skills, 2002, p. 4). Vockley (2007, p. 15) argues that schools that provide networked education enable personalized and equitable learning opportunities for students. When students experience a seamless digital ecology that transcends boundaries there are increased opportunities for authentic and meaningful learning to occur.

Perhaps because of the desire to emphasize digital experiences, some schools have taken a radical response to technology. Just over $5 \%$ of survey respondents predicted that ebooks would make up $80 \%$ or more of their school collection, with 2 schools predicting $100 \%$ digital collection by 2020 due to "school wishing to go totally digital and paperless" (QLD F-12 Independent), and "the deputy principal pushing digital resources and insisting on culling huge numbers of books" (NSW Independent Primary). Besides school management pushing for ebooks (5), schools referenced their existing strong digital collection (3), ease of use and management (2) and user preference (3). Others in this band refer to trends in technology and publishing (6) reporting "circulation of hard copy non-fiction is crashing" (QLD independent F-12) and "rapid growth and establishment of infrastructure, clients also becoming more familiar with the format" (Vic Catholic secondary).

However, the growth in technology in both the home and school environments provides increased opportunities for students and educators to interconnect their learning through the 'third space' as a place where different cultures meet. Millard (2003) argues that students' home and social interests, brought to classroom literacy learning, are influenced by access to 
new technologies and engagement with popular culture. One strategy to make connections between home and school experiences is through the use of technology for reading - for both recreational and academic purposes.

Complexities around the range of ebooks are further complicated when you factor in the reading purposes ranging from teaching literacy skills, supporting curriculum programs (factual and class literature) and personal reading. A particular issue revealed in the 50:50 by 2020 survey was the management of digital textbooks. The trend in Australia is for students to have a direct log in to access these online, although the format may range from a digital book that is read online, a downloadable pdf that students save to their hardware, or a CDROM.

Free ebooks are attractive as they may be read online or downloaded and the sites may be catalogued with a direct link provided or made accessible as a link on the school or library's learning management system. Purchased PDF ebooks need to be managed within the school's network and the school needs to ensure that digital rights protocols are in place or limit purchases to ebooks that have a campus license. Enhanced books available as apps require downloading to individual devices, often with regular updates, and management through an account with the provider. Management of enhanced ebook apps is restrained by provider protocols and often require individual management on each device. Regardless of the systems adopted, the library needs to facilitate home access and establish methods to promote ebooks in new and exciting ways, harnessing technology to do so. Questions arise as to how schools manage these for home access.

Technology, and the school's stance on the use of personal devices in the school, also impacts on collection development decisions. Equipment includes personal computers, laptops, tablets, ereaders and smart phones, and their operating systems., Some ebooks are platform specific and some operate across different platforms (Cavenaugh, 2005, p. 56). Uniform standards for ebooks are still developing and enhanced books with media rich features add further complexities.

It is important that ebook collections address popular culture reading material as well as subject content and etextbook resources. Access to high-interest digital fiction that is portable between and across devices encourages students to read recreationally and bring alternative and personal literary experiences to the classroom. However, publishers are currently dictating the market and individual feedback from the survey indicates that lack of access to popular titles impinges on students' interests in, and take-up of, ereading for recreational purposes. Open access is helping schools meet these challenges with $36 \%$ of the respondents to the 50:50 in 2020 survey reporting that they use Project Gutenberg as an ebook provider, which was higher than all but one commercial provider out of a list of 19 options. A learning ecology that supports learners in multiple environments requires the capability to download ebooks to both school equipment and home devices through a library management system that is accessible 24/7. So 'free and flexible' from Project Gutenberg provides any school library the option to make a start in the use of digital ebook resources.

School library collection development presents some unique circumstances and challenges that encompass national curriculum requirements through to specific community needs (Sheehan 2013, p. 81). Customizing collections requires meeting departmental standards, 
providing curriculum relevant content for the breadth of age and ability in the school cohort, responding to the recreational interests of students, supporting the teaching and professional learning requirements of teachers and addressing unique local community aspects. Ebooks are not necessarily available to address this breadth in collection development. Added to this, are issues on ebook publishing formats, digital rights management and the subsequent borrowing restrictions that do not adequately address the way schools and students interact with and use texts.

\section{Conclusion}

The digital future of school libraries presents a vision of rich, diverse and multimodal collections, where eresources contribute to new cultures of reading and learning. The feedback received from Australian schools via the 50:50 by 2020 survey indicates that for most schools there is some way to go before the breadth of this vision is realized.

What is encouraging is the evidence that teacher librarians are responding to the ereading challenges, and adapting library collections. Nevertheless, while the survey shows a steady increase in the implementation of ebooks over the past two years, the qualitative responses reveal schools grappling with significant issues related to collection building, collection management and use of digital resources. There are also glimpses of libraries that are making headway with these issues as they immerse themselves in the digital space. A challenge for the school library sector is to respond to these findings and promote opportunities for school library staff to share what works, and to learn from each other's experience.

Given the pace at which technology changes progress, it is essential that school libraries keep abreast of the changes and developments taking place and ensure that collections remain responsive to needs for literature in digital environments. While there is no way to predict the technologies of the future, it is important to consider the ways that students will read in the future; the changes that need to be made to incorporate literature into curriculum and learning experiences; and how the library collection can support and create engaging, innovative experiences for students. Australian school libraries are travelling towards exciting new futures for library collections - yet in many ways the journey has just begun!

\section{References}

ACARA (Australian Curriculum and Reporting Authority) (2014). Australian Curriculum V7.2 English: Aims. Retrieved from http://www.australiancurriculum.edu.au/english/aims.

Australian Library and Information Association (2013). 50:50 by 2020. Retrieved from http://www.alia.org.au/sites/default/files/documents/about/ALIA-5050-by$\underline{2020 \text { 2.pdf. }}$

Bain, A., \& Weston, M. (2012). The learning edge: What technology can do to educate all children. New York: Teachers College Press.

Barron, B. (2006). Interest and self-sustained learning as catalysts of development: A learning ecology perspective. Human Development, 49, 193-224. 
Cahill, M., \& Richey, J. (2014, August). Do you hear what I hear? Questioning the legitimacy of audiobooks as 'reading' material. Paper presented at IFLA Satellite Conference: Libraries For Children And Youth And School Libraries Section, Lyon, France. Retrieved from http://www.reseau-canope.fr/ifla-seminairebnf/pdf/cahill article.pdf.

Cavenaugh, T. (2005). The Digital reader: Using e-books in K-12 education. Eugene, OR: ISTE.

Clyde, L. A. (1981). The magic casements: A survey of school library history from the eighth to the twentieth century (Unpublished doctoral dissertation). James Cook University, Townsville. Retrieved from http://researchonline.jcu.edu.au/2051/1/01front.pdf.

DEEWR (Department of Education, Employment and Workplace Relations). (2014). Chapter 2 Impact of Recent Commonwealth Government Policies and Investments on School Libraries. Submission 344.1. p. 2 to the inquiry of the House of Representative Committee on school libraries and teacher librarians in 21st century Australia. Retrieved from http://www.aph.gov.au/parliamentary business/committees/house of representati ves committees?url=ee/schoollibraries/report/chapter2.htm.

Felvegi, E., \& Matthew, K. I. (2012). Ebooks and literacy in K-12 schools. Computers in the Schools, 29, 40-52. doi: 10.1080/07380569.2012.651421.

Gogan, B., \& Marcus, A. (2013). Lost in transliteracy. Knowledge Quest, 41(5), 40-45.

Gordon, C. (2010). The culture of inquiry in school libraries. School Libraries Worldwide, 16(1), 73-88.

Hay, L., \& Foley, C. (2009). School libraries building capacity for student learning in 21C. Scan, 28(2), 17-26.

Johnson D. (2013). Top ten school library game changers of the past twenty-five years. Teacher Librarian, 40(4), 28-31.

Johnson, P. (2014). Fundamentals of collection development and management 3rd ed.. Chicago: American Library Association.

Lamb, A. (2011). Reading redefined for a transmedia universe. Learning \& Leading with Technology. 39(3), 12-17.

Lamb, A., \& Johnson, L. (2010). Divergent convergence Part 2: Teaching and learning in a transmedia world. Teacher Librarian, 38, 64-9.

Larson, L. (2009). E-reading and e-responding: New tools for the next generation of readers. Journal of Adolescent \& Adult Literacy, 53(30), 255-258. doi:10.1598/JAAL.53.3.7.

Marcoux, E., \& Loertscher, D. (2009). The role of a school library in a school's reading program. Teacher Librarian, 37, 8-14. 
McAllan, T. (2013). Snapshots of learning in the library and classroom: E-books in a history unit - a case study. In J. Bales (Ed.), E-books in learning: A beginners guide (pp. 29-31). Sydney, NSW: Australian School Library Association.

Millard, E. (2003). Towards a literacy of fusion: New times, new teaching and learning? Reading, 37, 3-8. doi: 10.1111/1467-9345.3701002.

Neale, I. (2001). School libraries the poor relation. Education Stuff NZ. Retrieved from http://www.stuff.co.nz/national/education/5602314/School-libraries-the-poorrelation.

O'Connell, J., Bales, J. \& Mitchell, P. (in press). [R]Evolution in reading cultures: 2020 vision for school libraries. Australian Library Journal.

Partnership for $21^{\text {st }}$ Century Skills. (2002). Learning for the 21 st century: A report and mile guide for 21 st century skills. Washington, DC: Partnership for $21^{\text {st }}$ Century Skills. Retrieved from http://www.p21.org/storage/documents/P21 Report.pdf.

Pinnell, G., \& Fountas, I. (2007). The continuum of literacy learning, Grades K-8: Behaviors and understanding to notice, teach and support. Portsmouth, $\mathrm{NH}$ : Heinemann.

Rapaport, L. (2011). Amazon.com says Kindle e-book sales surpass printed books. Bloomberg Business, 19 May. Retrieved from http://www.bloomberg.com/news/articles/2011-05-19/amazon-com-says-kindleelectronic-book-sales-surpass-printed-format.

Reid, K. (2013). Creating e-books in the classroom. In J. Bales (Ed.), E-books in learning: A beginners guide (pp. 37-43). Sydney, NSW: Australian School Library Association.

Reynolds, S., \& Carroll, M. (2012). Collaborators or competitors? The roles of school libraries, classroom libraries, teachers and teacher librarians in literacy development. Synergy, 10(1). Retrieved from http://www.slav.vic.edu.au/synergy/volume-10-number-1-2012/research/235collaborators-or-competitors-the-roles-of-school-libraries-classroom-librariesteachers-and-teacher-librarians-in-literacy-development.html.

Rosenblatt, L. (1995). Literature as exploration (5th ed.). New York: Modern Language Association.

School Library Journal. (2014). Survey of ebook usage in U.S. school libraries: Fifth annual survey. Retrieved from http://www.thedigitalshift.com/research/ebook-usage-u-sschool-k-12-libraries-2014-report.

Sheehan, K. (2013). The ebook revolution: A primer for librarians on the front lines. Santa Barbara, CA: Libraries Unlimited. 
Softlink. (2014a). 2013 Australian school library survey. Softlink. Retrieved from http://www.softlinkint.com/2013-australian-school-library-survey-schools.

Softlink. (2014b). The 2014 Australian school library survey summary. Softlink. Retrieved from http://www.softlinkint.com.

Strick, A. (2013). Is everybody in? Part 2. Making our school library collection truly inclusive. School Librarian, 61(4), 198-99.

Thomas, D., \& Brown, J. (2011). A new culture of learning: Cultivating the imagination for a world of constant change. Lexington, Ky: Create Space.

Todd, R. \& Gordon, C. (2010. School libraries, now more than ever: a position paper of the center for international scholarship in school libraries. Center for International Scholarship in School Libraries, Rutgers University. Retrieved from http://njasl.info/wp-content/NJ study/Oct2012 CISSL.pdf

Vandergrift, K. (1996). Vandergrift's reader response criticism and resources. Retrieved from http://comminfo.rutgers.edu/professional-development/childlit/readerresponse.html.

Vockley, M. (2007). Maximizing the impact: The pivotal role of technology in a 21st century education system. Partnership for 21st Century Skills. Retrieved from http://www.p21.org/storage/documents/p21 setdaistepaper.pdf.

\section{Biographical notes}

Judy O'Connell has worked as lecturer and Courses (programs) Director at Charles Sturt University since 2011. From 2008-2010 she was Head of Library and Information Services at St Joseph's College, Hunters Hill, Sydney. In 2006-2007 she was an Education Consultant in Library and Web 2.0 developments for 80 primary and secondary schools in the Western Region of Sydney. Her professional leadership spans school and tertiary education, with a focus on libraries, learning spaces, online learning design, innovation, social media and technology for learning and teaching. In 2014 she received a Charles Sturt University Faculty of Education Award for Academic Excellence.

Dr Jennie Bales has worked as an adjunct lecturer in the School of Information Studies at Charles Sturt University since 2014. Prior to that a long career as a teacher librarian for the Department of Education Tasmania has included school leadership in the primary and secondary sectors, predominantly around the integration of ICT into teaching and learning. Her professional and research interests revolve around online and digital learning, curriculum resourcing and children's literature with several action research investigations conducted within schools.

Pru Mitchell is Manager of Information Services at the Australian Council for Educational Research in Melbourne and an adjunct lecturer, School of Information Studies at Charles Sturt University in Wagga Wagga. Her professional and research interests include metadata, education librarianship, collection management and professional learning. After working as a teacher librarian across K-12, Pru spent twelve years managing national online education 
projects including the Schools Catalogue Information Service. In 2010 she received the Australian School Library Association Citation. 